

\section{EXPEDIENTE}

Universidade do Estado do Rio de Janeiro - UERJ

Instituto de Estudos Sociais e Políticos - IESP

CADERNOS DE ESTUdOS SOCIAIS E POLÍTICOS www.e-publicacoes.uerj.br/index.php/CESP

\section{COMITÉ EDITORIAL}

Anna Carolina Venturini, IESP-UERJ

Felipe Munhoz de Albuquerque, IESP-UERJ

Leonardo Nóbrega da Silva, IESP-UERJ

Marcelo Borel, IESP-UERJ

Marcia Rangel Candido, IESP-UERJ

Marina Rute Pacheco, IESP-UERJ

Mariane Silva Reghim, IESP-UERJ

Natália Leão, IESP-UERJ

Paulo Joaquim Da Silva Rodrigues, IESP-UERJ

Raul Nunes de Oliveira, IESP-UERJ

\section{CAPA, LAYOUT E DIAGRAMAÇÃO}

Marcia Rangel Candido

Raul Nunes de Oliveira 


\section{Apresentação}

Mariane Silva Reghim

\section{Dossiê}

É Possível Fazer Ciências Sociais sem uma Análise Crítica das

Categorias de Diferenciação? Uma Proposição Feminista

Natália Corazza Padovani

As Perspectivas Teóricas Queer e o Uso Cotidiano da Língua

Portuguesa

Helza Ricarte Lanz e Juliane Noack Napoles

Raça e Violência Sexual: Âmbito de Aplicação da Vitimodogmática?

Amanda Bessoni Boudoux Salgado e José Roberto Macri Jr.

What Happened with "What Happened, Miss Simone?"? - Assistindo ao Documentário Pela Ótica do Feminismo Negro

Rafael Pinto Ferreira de Queiroz

O Racismo Institucional no Brasil: Contribuições de Louis Althusser para o Debate

\section{Artigos}

O Voto Econômico na América Latina entre 2004 - 2012: Avaliação da Economia e do Desempenho do Governo em Políticas Públicas e de Combate à Corrupção

Flávia Bozza Martins

Eleições Presidenciais de 2014: Reflexões sobre o Capital Político e a

Capitalização de Votos de Marina Silva

Bruno Fonseca Gurão e Mirna Tonus

\section{Resenha}

Neoliberalismo Desde Baixo, Pós-Fordismo Periférico e Cálculos Emancipatórios

Igor Peres

Sobre Autogestão nas Fábricas Recuperadas no Brasil: (R)Existindo no Mercado 


\title{
Raça e Violência Sexual: Âmbito de Aplicação da Vitimodogmática?
}

\author{
Race and Sexual Violence: a Victimodogmatic Perspective?
}

\author{
Amanda Bessoni Boudoux Salgado \\ José Roberto Macri Jr. ${ }^{2}$
}

\section{RESUMO}

O objetivo deste trabalho é analisar como a raça pode influenciar na aplicação da lei nos casos de violência sexual. Para tanto, parte-se da concepção da vitimodogmática como teoria que valora o comportamento da vítima para aferição da responsabilidade do agressor. Pretende-se estudar quais comportamentos das vítimas são levados em consideração nos casos de estupro, discutindo se esses comportamentos são efetivamente jurídico-penalmente relevantes. A intersecção entre raça e violência sexual será discutida precisamente em dois pontos: (I) sob a perspectiva do homem negro, com a construção do estereótipo do agressor sexual, tem-se que a palavra da vítima tende a ganhar credibilidade e o comportamento da ofendida torna-se irrelevante; (II) sob a perspectiva da mulher negra, tem-se uma maior desproteção legal, haja vista que comportamentos mal valorados em uma análise vitimodogmática são pressupostos.

PALAVRAS-CHAVE: Raça; Violência sexual; Interseccionalidade; Vitimodogmática.

\begin{abstract}
The purpose of this article is to analyze how race can influence law enforcement in cases of sexual violence. Therefore, it is based on the conception of victimization as a theory that values the behavior of the victim in order to assess the responsibility of the aggressor. We intend to study which behaviors are taken into account in cases of rape and thus to discuss whether these behaviors are effectively legally relevant. The intersection between race and sexual violence will be discussed precisely in two points: (I) from the perspective of the black man, with the construction of the stereotype of the sexual aggressor, we have that the victim's word tends to gain credibility and the behavior of the offended person becomes irrelevant; (II) from the perspective of the black woman, there is a greater lack of legal protection, considering that undervalued behaviors in a vitimodogmatic analysis are presupposed.
\end{abstract}

KEYWORDS: Race; Sexual violence; Intersectionality; Vitimodogmatic.

1 Graduada em Direito pela Universidade Estadual Paulista Júlio de Mesquita Filho - UNESP/Franca. Doutoranda em Direito Penal, Medicina Forense e Criminologia pela Faculdade de Direito da Universidade de São Paulo. E-mail: amandabessonibs@gmail.com

2 Graduado em Direito pela Faculdade de Direito de Ribeirão Preto - FDRP/USP. Doutorando em Direito Penal, Medicina Forense e Criminologia pela Faculdade de Direito da Universidade de São Paulo. E-mail: macrijunior@hotmail.com 


\section{INTRODUÇÃO}

No âmbito das ciências jurídico-criminais, o estabelecimento dos comportamentos da vítima que podem influenciar na responsabilidade penal do autor é dado pela chamada “vitimodogmática". Tem o mérito, assim, de evitar a criação de assimetrias de deveres entre os envolvidos no delito. Contudo, um uso abusivo da teoria pode criar graves lacunas de tutela jurídica, sobrecarregando a vítima de deveres de autoproteção. Tal pode se dar, por exemplo, nos delitos sexuais, nos quais muitas vezes comportamentos cotidianos são indevidamente considerados como autocolocação em risco.

No caso específico dos delitos sexuais, objeto deste trabalho, a valoração negativa de certas atitudes correntes (por exemplo, pedir carona, consumir álcool, usar determinados tipos de roupa) é dogmática e político criminalmente equivocada. Afinal, não se pode tratar como autocolocação em risco o mero exercício das liberdades de locomoção, de modo de vida, de escolha do vestuário, por exemplo. O que ocorre, na verdade, é que a mulher que foge aos padrões estabelecidos socialmente, muitas vezes, não é reconhecida como vítima.

Tal situação é ainda mais evidente quando presente o componente racial. Com efeito, a mulher negra tem contra si a presunção de fuga dos padrões da vítima ideal. Dessa forma, a mulher negra nem sempre tem a "chance" de não ser avaliada por seu comportamento ou pela sua própria imagem (algo que não deveria ocorrer em nenhum caso de violência sexual).

Se o componente racial, por um lado, cria lacunas de proteção em relação à mulher negra, por outro lado, aliado à não individualização do homem negro e à construção do estereótipo de sexualidade selvagem, favorece a persecução penal indiscriminada das populações negras, haja vista que "qualquer um pode ser culpado".

A valoração dos corpos dos envolvidos revela uma série de preconceitos, cujas raízes são profundas. Entretanto, a discriminação não pode ser explicitada em decisões judiciais. A vitimodogmática, assim, pode ter a função de legitimar e racionalizar preconceitos, conferindo ares de ciência jurídica ao racismo e ao machismo. 


\section{CONSIDERAÇÕES DA PERSPECTIVA VITIMODOGMÁTICA}

\section{O CONCEITO DE VITIMODOGMÁTICA}

A consolidação do direito penal como direito público delimita este ramo como aquele que trata da relação autor-Estado, colocando um fim ao direito penal da vingança privada, o qual coincide com o que se conhece como "idade de ouro" da vítima (Oliveira, 1999). Procura-se, dessa forma, obter uma justiça penal objetiva e desapaixonada, isto é, não influenciada por um suposto desejo de vingança da vítima (Silva Sánchez, 2001a).

Tal configuração da resposta penal, ou seja, a neutralização da ânsia punitiva da vítima junto à apropriação do conflito pelo Estado, acaba por deixar o sujeito passivo do delito em uma posição periférica, passando a desempenhar um papel circunstancial, meramente informativo. Desde o fim da Segunda Guerra Mundial, entretanto, e mais acentuadamente nas últimas décadas, há o movimento de "redescobrimento da vítima" no direito penal - o movimento vitimológico ${ }^{3}$, o qual teve uma série de impactos nas ciências penais. Com efeito, no âmbito da política criminal, em um contexto de crescente identificação da sociedade com a vítima do delito (Del Rosal Blasco, 2009; Silva Sánchez, 2001b), há a configuração das chamadas políticas de exclusão (Oliveira, 1999) ${ }^{4}$, as quais consistem basicamente na contraposição dos direitos das vítimas aos direitos dos criminosos. Assim, crescem os clamores, por exemplo, pela redução das garantias processuais (Pastana, 2003; Amaral, 2007; Mendonza Buergo, 2001; Diéz Ripollés, 2008) e, consequentemente, pela maior eficiência do direito penal ${ }^{5}$. Por outro lado, em contraposição às políticas de exclusão, ganham força os questionamentos acerca da finalidade da pena (Bung, 2016), bem como a criação de novas medidas tendentes a proporcionar uma maior satisfação à vítima (Oliveira, 1999). Assim, as políticas de inclusão fundamentam-se na constatação vitimológica de que o sistema penal como um todo não repara o dano sofrido pela

3 Schmidt de Oliveira critica a terminologia "redescobrimento" por entender que o movimento vitimológico contemporâneo tem características bastante peculiares para ser chamado de "redescobrimento". Mais adequado, dessa forma, seria falar em "movimento vitimológico" (Oliveira, 1999, p. 58).

4 Para uma abordagem psicológica das raízes das políticas de exclusão, pautadas no desejo de vingança, ver Darley, 2009.

5 Evidentemente, o ideal de eficiência atuarial do direito penal pode ocasionar restrições ilegítimas das liberdades individuais. Nesse sentido, ver: Hassemer, 1999; Husak, 2008; Bottini, 2007. 
vítima, podendo, inclusive, agravar sua situação durante a reação penal pela chamada "vitimização secundária” (Silva Sánchez, 2001a) ${ }^{6}$.

O movimento vitimológico demonstrou que a vítima não é sempre um mero objeto passivo sobre o qual casualmente recai o delito, mas sim que em algumas ocasiões o crime pode ser produto de uma certa interação entre o autor e a própria vítima (Silva Sánchez, 2001a). Assim, a vitimodogmática procura avaliar como o comportamento da vítima repercute na valoração jurídico-penal do comportamento do autor (Silva Sánchez, 2001a). Dessa maneira, coloca-se o chamado "dilema vitimodogmático". Por um lado, tem-se que a ampla responsabilização do autor quando há também responsabilidade da vítima torna a sanção ilegítima, por ser desproporcional. Por outro lado, tem-se que a culpabilização da vítima traz enormes prejuízos psicológicos e sociais, tais como a perda de confiança na tutela penal (Silva Sánchez). Necessário se faz, assim, delimitar o âmbito de aplicação da vitimodogmática.

Segundo Silva Sánchez (2001a), a doutrina dominante entende que a vitimodogmática pode influir no quantum da pena aplicada ao autor. Entretanto, há uma corrente minoritária que defende que o comportamento da vítima pode implicar isenção de responsabilidade do autor do delito. Os adeptos desta última apenas defendem a aplicação das considerações vitimodogmáticas aos chamados delitos de relação (Bez̧iehungsdelikte $)^{7}$, não aos delitos de intervenção (Zugriffsdelikte) $8^{8}$. Dessa forma, somente nos casos em que o delito requer para sua consumação uma participação da vítima, o princípio vitimodogmático (autorresponsabilidade) seria levado em consideração (Silva Sánchez, 2001a; Machado Rodríguez, 2010; Hernández Hidalgo, 2015).

Todavia, a mera distinção entre delitos de relação e de intervenção não basta para "salvar" a vitimodogmática das críticas de seus opositores. Com efeito, a manutenção da regra informal de que quanto mais intensa a relação entre autor e vítima, maiores serão as exigências probatórias da materialidade da infração, pode levar ao fenômeno da "bagatelização dos delitos de relação" (Frommel, 1987) ${ }^{9}$. Deve-se, portanto, definir com adequada precisão o conteúdo das chamadas "medidas de proteção". Assim, pode-se ver como algo exigível, em certa medida, que não se realizem atos dolosos ou imprudentes que direta ou indiretamente possam provocar a lesão dos próprios bens jurídicos por terceiros (Pawlik, 2010). A vítima, contudo, não deve ficar

6 Sobre os reflexos legislativos das políticas de inclusão, ver Oliveira, 1999, pp. 128 e ss.

$7 \quad$ O estelionato é o exemplo paradigmático dos delitos de relação (Herrera Moreno, 2001, p. 91).

8 Seria o caso, por exemplo, do estupro.

9 Esta questão será discutida com maiores detalhes com a distinção proposta por Estrich entre estupro simples e estupro grave. 
sobrecarregada de deveres excepcionais de autoproteção. Trata-se, sim, de uma distribuição ponderada de responsabilidades segundo o critério estrito de proporcionalidade (Silva Sánchez, 2001a $)^{10}$.

Como teoria de legitimação da sanção, a vitimodogmática afirma que não se pode apenar uma conduta quando existem possibilidades de autoproteção da vítima, porque a lesão do bem jurídico recai em seu âmbito de responsabilidade, não no do autor. As ideias de âmbitos de responsabilidade, contudo, somente podem enriquecer a discussão sobre a legitimidade da punição quando: i) a estrutura do delito faça necessária a participação da vítima (como ocorre, por exemplo, no estelionato, ainda que seja induzida a erro); ii) quando se dá a participação da vítima em certas situações típicas (e.g. lesões corporais decorrentes de autocolocação em perigo) ${ }^{11}$; ou iii) quando são várias as pessoas que intervêm na lesão do bem jurídico ou interesse. Nos casos em que a vítima figura apenas como titular do bem jurídico, a referência a âmbitos de responsabilidade não traz nenhuma melhora dogmática (Wittig, 2007). Assim, o abandono ao paradigma da agressão deve ser apenas parcial ${ }^{12}$, pois, do contrário, corre-se o risco de negar proteção a diversas vítimas (Wittig, 2007).

\section{VITIMODOGMÁTICA E DELITOS SEXUAIS}

O estupro é geralmente estudado como o clássico tipo de delito sexual, tendo em vista ser expressão da mais acentuada violência contra a autodeterminação sexual das pessoas, muito embora a discussão acerca do bem jurídico tutelado pelos delitos sexuais seja, ainda hoje, bastante intensa (Roxin, 1997; Silveira, 2008).

Certo é que, durante um longo período, que em muitos aspectos se estende até os dias atuais, as questões concernentes à sexualidade permaneceram atreladas a um sentido de moralidade, adstrito ao que a sociedade julgava ser aceitável ou "normal". Os reflexos legislativos deste entendimento eram nítidos, a exemplo do conceito de "mulher honesta" 13 e da classificação

10 Portanto, a vitimodogmática não deve ser confundida com um reavivar da ideia de blaming the victim (Oliveira, 1999).

11 Para uma exposição ampla acerca do risco criado pela própria vítima, ver Gimbernat Ordeig, 2005.

12 Sobre o paradigma da agressão, ver Kindhäuser, 2008.

13 Até 2005 o Código Penal trazia a terminologia "mulher honesta", a qual seria merecedora de proteção nos crimes de posse sexual mediante fraude e atentado violento ao pudor mediante fraude. Para Nelson Hungria (1981, p. 139), seria mulher honesta "não somente aquela cuja conduta sob o ponto de vista da moral é irrepreensível, senão também aquela que não rompeu com um minimum de decência exigida pelos bons costumes". A contrario sensu, mulheres desonestas - tidas como as prostitutas e as mulheres de "vida desregrada" - não poderiam ser sujeitos passivos de tal crime. Não seria exagero afirmar que a norma penal não as abarcava porque considerava suas 
dos delitos sexuais como "crimes contra os costumes" (denominação que vigorou até 2009, quando a Lei 12.015/2009 alterou o Título VI do Código Penal Brasileiro, passando a tratá-los como "crimes contra a dignidade sexual"). A influência da moralidade, além de provocar o aumento da cifra oculta de crimes sexuais ${ }^{14}$, trazia graves prejuízos às vítimas em razão da falta de assistência médica e sobretudo jurídica. Basta recordar, neste sentido, que até pouco tempo atrás não era considerado estupro o ato sexual forçado entre marido e esposa, pela existência de uma relação íntima na qual a relação sexual era caracterizada como um dever conjugal.

Susan Estrich (1987) diferencia estupro grave do estupro simples (simple rape). O primeiro tipo é relativamente raro, perseguido e punido rigidamente pela justiça e apresenta uma baixa cifra oculta (isto é, quase sempre é reportado). O estupro grave é o caso em que um ou mais homens atacam uma mulher desconhecida, usando de violência ou ameaça com armas. O segundo tipo caracteriza-se pela ausência de agressão física e pelo fato de autor e vítima se conhecerem. Há apenas ausência de consentimento. Nesses casos, raramente a vítima se enxerga como vítima de um crime (sendo, portanto, elevada a cifra oculta), o autor acredita agir adequadamente e, o mais grave de tudo, o sistema penal costuma demonstrar indiferença ${ }^{15}$. Eis o modo como o estupro (simples) pode ser exemplo da bagatelização dos delitos de relação ${ }^{16}$.

À exceção das hipóteses de homicídio, um relacionamento preexistente entre autor e vítima geralmente torna o delito menos reprovável, segundo algum entendimento ainda persistente. Há razões, segundo Estrich (1987), que oferecem suporte a essa visão. Cada uma delas, quando aplicadas ao estupro, incorporam as ideias de poder masculino e "comportamento faltoso/reprovável" da vítima. Em primeiro lugar, alguns casos de relações preexistentes são menos reprováveis por identificar-se certo "direito" a agir de determinada forma, direito este que um estranho não teria. Esse raciocínio, todavia, não pode ser incorporado à lógica do estupro. $\mathrm{O}$ fato de uma mulher ter consentido em uma relação sexual com determinada pessoa não implica

condutas arriscadas, ou seja, essas mulheres, segundo o entendimento até muito recentemente refletido na legislação, não se protegiam como deveriam, colocando-se em uma situação de risco - o que, nesses tipos, eximiria a responsabilidade do autor e tiraria qualquer responsabilidade do Estado de averiguar essas condutas.

$14 \quad$ A cifra oculta diz respeito à quantidade de crimes praticados que não chega ao conhecimento das autoridades. Embora seja extremamente complexa a abordagem do tema da violência sexual em pesquisas nacionais de vitimização, por exemplo, em estudo coordenado pelo Instituto de Pesquisa Econômica Aplicada (Cerqueira \& Coelho, 2014, p. 6), no ano de 2013, estimou-se que somente $10 \%$ dos estupros consumados são reportados às autoridades policiais.

15 Estrich (1987, p. 12) aponta, ainda, para o fato de que o número de mulheres violadas por conhecidos que procuram centros de ajuda é muito maior do que o de mulheres em situações semelhantes que procuram as autoridades. Isto revela que muitas mulheres se enxergam como vítimas, contudo, não como vítimas de um crime.

16 Com efeito, problema grave da resposta do sistema penal às vítimas de simple rape é a discricionariedade da polícia. Isto porque a polícia decide o que e como investigar, avalia se o relato da vítima tem ou não fundamento etc (Estrich, 1987, p. 15). 
um direito de acesso sexual perpétuo. Em segundo lugar, comportamentos das partes de uma relação preexistente podem certamente ter relevância penal, independentemente do vínculo. Em verdade, nenhuma conduta da mulher pode ser interpretada, segundo critérios pessoais, como consentimento ou provocação. Por fim, diz-se que um ataque de um conhecido é menos traumático para a vítima. Contudo, o medo de ser atacado por estranhos fundamenta-se basicamente na ideia de que nenhum conhecido possa nos fazer mal. Quando esta expectativa é frustrada, não há razão para se acreditar que o trauma seja menor do que o causado por um ataque de um desconhecido (Estrich, 1987).

Assim, colocam-se as seguintes questões: haveria deveres de autoproteção da vítima no delito de estupro? E é possível aventar a hipótese de colocação da vítima em risco? Há algo, além do expresso consentimento da vítima, que o julgador deveria considerar para caracterização de existência ou não do delito? Há critérios para diminuição de pena do autor? Pode-se, inicialmente, identificar três correntes doutrinárias acerca da aplicação do princípio de autorresponsabilidade no delito de estupro. Uma primeira corrente entende ser inaplicável e político-criminalmente desaconselhável qualquer indagação vitimodogmática acerca deste crime; uma corrente intermediária entende ser possível uma aplicação restrita da vitimodogmática nesse âmbito; por fim, há quem entenda ser sempre possível ponderar a responsabilidade do autor em face do comportamento da vítima. A ideia fundamental da primeira corrente é a de que mitigações de responsabilidade do autor em um delito no qual a vítima figura apenas como detentora do bem jurídico lesionado traria enormes prejuízos político-criminais e sociais. Afirmase que haveria uma perda de confiança no (e, no limite, de função do) direito penal, pois a vítima, de alguma maneira, seria responsável por sua própria segurança (Wittig, 2007). A corrente intermediária entende que o princípio de autorresponsabilidade deve ser considerado, nos delitos de estupro, apenas em circunstâncias muito restritas e delimitadas. Assim, e.g., María Elena Santibáñez Torres (2010) entende que as indagações vitimodogmáticas somente devem ter espaço quando a própria vítima tem a iniciativa da relação sexual e, durante o ato ou pouco antes de iniciá-lo, desiste. Desde um ponto de vista vitimodogmático, pode-se sustentar que neste caso a vítima, com seu comportamento, contribuiu para a lesão do bem jurídico. Todavia, não se pode negar que nesta situação ainda há delito, uma vez que a pessoa sempre conserva sua liberdade de autodeterminação sexual, podendo, portanto, a qualquer momento, retirar seu consentimento. A solução, assim, seria apenas uma redução da pena aplicada ao autor, não a isenção de sua responsabilidade. Há ainda uma terceira corrente, bastante ultrapassada, segundo a qual o comportamento da vítima é fundamental para a compreensão do delito de estupro. Assim, José 
Guilherme de Souza (1998), por exemplo, afirma que o estupro, muitas vezes, decorre de uma falha de comunicação entre autor e vítima. Segundo o autor, o comportamento, o histórico sexual e mesmo a maneira de se vestir da vítima poderiam causar uma impressão de "consentimento tácito" no autor ${ }^{17}$. Correlata a essas questões, ou até mesmo, em alguma medida, abarcando todas as anteriores, coloca-se a questão do consentimento. O entendimento majoritário é o de que o consentimento apenas descaracteriza o delito quando recai sobre bens jurídicos disponíveis, o que não é o caso da dignidade sexual. Contudo, evidentemente, há que se reconhecer uma ampla liberdade individual para ingressar em atividades de natureza sexual, sob pena de, não o fazendo, instituir-se um inadmissível moralismo penal19-20. O ponto a ser debatido, portanto, é a aferição do consentimento.

A conduta da vítima e a sua reputação moral, não raramente, são fatores considerados para avaliar a culpabilidade do autor ${ }^{18}$. Correlata a essas questões, ou até mesmo, em alguma medida, abarcando todas as anteriores, coloca-se a questão do consentimento. O entendimento majoritário é o de que o consentimento apenas descaracteriza o delito quando recai sobre bens jurídicos disponíveis, o que não é o caso da dignidade sexual. Contudo, evidentemente, há que se reconhecer uma ampla liberdade individual para ingressar em atividades de natureza sexual, sob pena de, não o fazendo, instituir-se um inadmissível moralismo penal ${ }^{19}{ }^{20}$. O ponto a ser debatido, portanto, é a aferição do consentimento.

Diversas autoras feministas têm feito severas críticas ao sistema penal pela forma como o consentimento é tratado em casos de delitos sexuais. Com efeito, há inúmeros casos em que a vítima não é reconhecida como tal por ter, "ainda que tacitamente”, consentido com o ato sexual, independentemente de manifestação expressa em sentido contrário. E mais, boa parcela da população manifesta opiniões análogas. Tal entendimento resulta, basicamente, de duas concepções errôneas. A primeira é de que determinados comportamentos da vítima podem ser interpretados como consentimento (Randall, 2010; Comack \& Peter, 2005). A segunda, conexa à primeira, é a que equipara consentimento e submissão. Assim, se não houver violência física,

17 Em sentido semelhante, Edgard de Moura Bittencourt (1978, pp. 242 e ss.) defende a ampla apreciação do comportamento e do histórico (sexual) da vítima. Ver também: Menachem, 1967, pp. 493 e ss.

18 Ainda hoje se trabalha com essa ideia de conduta de risco da mulher. Os critérios para determinar o grau de risco a que a mulher se expõe são basicamente três: (I) profissão; (II) deslocamentos diários; e (III) modo de locomoção (por exemplo, nesses termos, pegar carona seria uma conduta de risco) (Meléndez-Cardona et al., 2014, passim). Evidentemente, tais critério podem auxiliar em políticas de prevenção ao crime. Todavia, seria pelo menos político-criminalmente inconveniente considerar tais critérios como casos de autocolocação da vítima em risco.

19 Afinal, é no "contexto de autodeterminação, base maior da dignidade da pessoa humana, que se deve encontrar a fronteira última do Direito Penal sexual” (Silveira, 2008, p. 168).

20 A próposito, conferir o debate entre Devlin (2010) e Hart (1987) ocorrido em meados do século XX. 
muitas vezes, considera-se que, na verdade, houve consentimento - ainda que tácito - da vítima (Ross, 2010).

Não foi por outra razão que Susan Estrich (1987), não sem um toque de ironia, estabeleceu o que se pode chamar "padrão mínimo" de proteção às vítimas de estupro. A autora propõe que, em todo caso no qual se discute se a vítima não estaria realmente consentindo, substitua-se o bem jurídico tutelado (dignidade sexual) pelo patrimônio. Exemplifica a autora: imagine-se que A marca um encontro com B. Posteriormente, no mesmo dia, A vai ao apartamento de B. Passado algum tempo, B sugere que A somente poderá sair do recinto se "consentir" em um ato sexual. Estrich afirma que, para não restar dúvidas acerca do caráter criminoso desse fato, deve-se imaginar que B exigiu dinheiro de A. Segundo a autora, tal substituição evidenciaria que, de fato, não houve consentimento válido e, portanto, houve delito (Carvalho \& Macri Júnior, 2017).

Dessa maneira, no estupro, percebe-se claramente que as discussões vitimodogmáticas camuflam o verdadeiro problema: o não reconhecimento da mulher como sujeito de direito e titular de um direito violado (Pateman, 1993; Silveira, 2008). Com efeito, o conceito de vítima é construído socialmente (Bijleved, 2007). O discurso vitimodogmático, no caso de estupro, procura atribuir relevância penal a comportamentos jurídico-penalmente indiferentes (tais como vestimentas e profissão). Busca-se esconder que, na verdade, faz-se um juízo moral da mulher atacada: se em alguma medida ela se afasta do estereótipo da figura feminina, não é plenamente reconhecida como vítima. Assim, afirma-se que a discussão sobre a participação da vítima no estupro impede que se reconheça que a etiologia da violação sexual está sobretudo na estrutura e na aprendizagem sociais (Schneider, 1994).

\section{RAÇA E VIOLÊNCIA SEXUAL}

Já foi dito muitas vezes que o corpo de delito ${ }^{21}$ em um estupro é o corpo da própria vítima. Sendo o exame de corpo de delito uma maneira de verificar a materialidade delitiva, isto é,

$21 \quad$ "O exame de corpo de delito é uma espécie de perícia que tem a finalidade de analisar e reunir os elementos científicos que comprovam a realidade material do crime. Esse exame representa uma prova técnica da materialidade do fato criminoso, ou seja, uma prova que procura determinar essa materialidade do fato criminoso, ou seja, uma prova que procura determinar essa materialidade com base em conhecimentos técnicos ou científicos. 
comprovar se o crime realmente ocorreu, o corpo da vítima pode ser relevante em questões probatórias. Contudo, muitas vezes, a análise que se faz no estupro não toma por base critérios científicos (e.g., procura de sinais de agressão ou verificação do trauma psicológico). O corpo da vítima é tratado como objeto carregado de valores e conceitos, de modo que a própria credibilidade da palavra da vítima, a depender de características físicas ou meramente aparentes, pode ser questionada.

Entretanto, não apenas o corpo da vítima, mas também o corpo do acusado é valorado, a despeito de qualquer relevância jurídica. A propósito, o impactante depoimento de Susan Estrich (1987) acerca do próprio estupro traz interessante consideração: a autora diz que, de certa forma, teve "sorte" por ter sido violentada por um homem negro, afinal, assim, poucos duvidaram de sua palavra.

O estudo "Estupro no Brasil: uma radiografia segundo os dados da Saúde", desenvolvido pelo IPEA a partir do exame de microdados do Sistema de Informação de Agravos de Notificação (Sinan), demonstra que, dentre as vítimas, predominam as mulheres e as pessoas negras. Estimou-se que $88,5 \%$ das vítimas detectadas eram do sexo feminino, e $51 \%$ dos indivíduos eram de cor preta ou parda (Cerqueira \& Coelho, 2014). A pesquisa, infelizmente, não traz informações sob a perspectiva das mulheres não brancas, mas oferece indícios relevantes para a caracterização do perfil majoritário das vítimas de estupro no Brasil, especificamente aquelas que buscam os estabelecimentos públicos de saúde ${ }^{22}$.

Diante de dados como estes, a presente seção procura analisar como a raça (i.e., a cor da pele, o fenótipo) pode influenciar na aplicação da lei nos casos de violência sexual.

\section{O HOMEM NEGRO}

Jennifer Wriggins (1983), ao estudar as questões envolvendo raça e violência sexual nos Estados Unidos, aponta que, durante o período da escravidão, o sistema legal travava seriamente apenas uma combinação de estupro: homem negro e mulher branca. A autora

Logo, trata-se de prova com elevado nível de credibilidade, proporcional à confiabilidade de que desfrutam a própria ciência e também a técnica nos tempos modernos" (Machado, 2013, p. 514).

22 Jackeline Romio critica as aproximações de pesquisas estatísticas que equiparam mulheres negras a mulheres brancas e/ou homens negros: "Esse tipo de abordagem é bem conhecido e recorrente no Brasil, principalmente na área de informações estatísticas sobre violência e saúde. Nelas, encontram-se dados sobre mulheres em geral, mas que revelam a experiência de vida das mulheres brancas ou dos negros no geral, demonstrando apenas a experiência de vida dos homens negros, acarretando com isso a invisibilidade e negligência no caso das análises sobre a mulher negra" (Romio, 2013, p. 138. 
ressalta que, embora a situação tenha mudado, este passado ainda tem efeitos incisivos no presente.

Com efeito, persiste o mito de que as mulheres brancas precisam de extrema proteção contra homens negros. Desde a elaboração do discurso colonial, cujo objetivo era "apresentar o colonizado como uma população de tipos degenerados com base na origem racial de modo a justificar a conquista e estabelecer sistemas de administração e instrução" (Bhabha, 2013), a sexualidade negra tem sido estereotipada como violenta, incontrolável, bestial e, por vezes, criminosa (Patton \& Snyder-Yuly) ${ }^{23}$. A preservação do estereótipo e do mito da sexualidade negra tem a função de manter a hegemonia do homem branco, responsável pela proteção das mulheres brancas, vulneráveis aos ataques dos homens negros ${ }^{24}$.

Conforme a literatura especializada, no contexto dos Estados Unidos, são mais comuns estupros de mulheres brancas por homens brancos do que de mulheres brancas por homens negros. Além disso, são mais comuns os estupros de mulheres negras por homens negros do que o estupro de mulheres brancas por homens negros. Portanto, a "mitologia" do negro sexualmente voraz e da mulher branca vitimada pode ser estatisticamente contestada (South \& Felson, 1990; Patton \& Snyder-Yuly, 2007). Em verdade, as explicações teóricas acerca do motivo de os homens negros tenderem a atacar preferencialmente as mulheres brancas revelam-se infundadas. O "black politicalization model”, segundo o qual os negros atacariam mais as mulheres brancas em áreas com maior tensão racial ${ }^{25}$ e o "sexual access model", segundo o qual os homens negros tenderiam a atacar mais as mulheres brancas

23 A propósito, Bhabha: "Um aspecto importante do discurso colonial é sua dependência do conceito de 'fixidez' na construção ideológica da alteridade. A fixidez, como signo da diferença cultural/histórica/racial no discurso de colonialismo, é um modo de representação paradoxal: conota rigidez e ordem imutável como também desordem, degeneração e repetição demoníaca. Do mesmo modo, o estereótipo, que é a sua principal estratégia discursiva, é uma forma de conhecimento e identificação que vacila entre o que está sempre 'no lugar', já conhecido, e algo que deve ser ansiosamente repetido... como se a duplicidade essencial do asiático ou a bestial liberdade sexual do africano, que não precisam de prova, não pudessem na verdade ser provados jamais no discurso" (Bhabha, 2013, p. 117). "African moral standards were described as ape-like and beastly. Perhaps, the issue of morality is best exemplified in the Englishman's popular narrative of African sexuality. Like other related themes, narratives of African sexuality essentially judged African standards of morality against what Europeans considered to be the superior forms found only amongst Europeans. African sexuality during the period of slavery was portrayed via literature as a characteristic symptomatic of an incurable black immorality" (Kalunta-Crumpton, 2010, p. 7).

24 'Because of this racist and sexist framing of media 'reports' in the United States, every time a Black man is accused of raping or attacking a White woman (whether true or not) historical patriarchal White supremacist stereotypes and myths are reinforced. In a social hierarchy that privileges Whites over non Whites and males over females, false accusations reinforce and thereby strengthen stories of Black men as sexual predators needing to be policed and women crying out for attention. In addition, false accusations reinforce the mediated perception that sexual assault crimes are rarely newsworthy, unless the framing involves a White female victim and Black male perpetrator" (Patton \& Snyder-Yuly, 2007, p. 867).

25 Ver Coetzee (2016). 
(paradigma de beleza feminina) em áreas nas quais os contatos cordiais são mais escassos, revelam-se falsas. Com efeito, em locais de maior tensão racial, os estupros inter-raciais são menos frequentes. Além disso, esta modalidade de estupro é mais comum em regiões onde há maior contato inter-racial (por exemplo, locais com alto índice de casamentos inter-raciais). Portanto, segundo South e Felson (1990) e Young (1980), o fator preponderante para a ocorrência da violência sexual inter-racial é precisamente o contato, isto é, a interação social entre brancos e negros.

Paradoxalmente, pesquisas revelam que as sentenças tendem a ser mais severas quando ocorre a combinação homem negro e mulher branca (Patton \& Snyder-Yuly, 2007) ${ }^{26}$. Tal fato contraria a concepção da pena como coação psicológica, pois, segundo essa teoria, a sanção mais severa deveria ser aplicada aos crimes com maior incidência para, assim, reduzir a criminalidade (Dias, 1999, p. 90). Entendemos que essa discrepância na severidade das punições decorre da permanência do mito do negro agressor. Efetivamente, muitas vezes, especialmente nos casos em que há dúvida acerca da identidade do agressor (negro), luta-se contra uma ideia preconcebida, de modo que o ofensor perde sua individualidade: todos os negros tornam-se suspeitos. Logo, desprezando-se a identidade do criminoso, qualquer homem negro pode servir como bode expiatório ${ }^{27}$.

\section{A MULHER NEGRA}

O dever legal da mulher de resistir ao sexo funcionava como uma regra para distinguir estupro de sedução e, assim, diferenciar "mulheres boas" de "mulheres más"228. Embora, em tese, não mais exista este dever legal de resistir, que foi substituído pelo dever do homem de perguntar expressamente se há consentimento, ainda ocorre uma avaliação da credibilidade da mulher,

\footnotetext{
26 "From slavery to the present day, the legal system has consistently treated the rape of white women by Black men with more harshness than any other kind of rape. The punishment for Black offender/white victim rape has ranged historically from castration, to death by torture and lynching, to executions. Today Black men convicted of raping white women receive longer prison sentences than other rape defendants. Innocent Black men also face the threat of racially motivated prosecutions" (Wriggins, 1983, p. 116).

$27 \quad$ Patton e Snyder-Yuly (2007, p. 879), a propósito, assim discorrem acerca de um caso no qual houve falsa denúncia de estupro coletivo, culminando em ampla perseguição de homens negros da região em que teria ocorrido o crime: "There was no specific identity. Every Black male on campus became a suspect. Robb collectively identified all Black males as the same by failing to give any type of description other than race and height. None of her Black males were fat, were bald, or had dredlocks, tattoos, or piercings. Even though none were described as wearing masks or anything else to hide or alter their identity, Robb was unable to provide any distinguishing features. This is especially significant because she reported she had a previous interaction with one of the 'kidnappers'. This description of Black men could be found in any macrocontext setting. The mythology of violent Black males continues".

28 É a chamada “madonna/whore dichotomy” (Crenshaw, 1991, p. 1280).
} 
tendo por base padrões de comportamento feminino. Daí, por exemplo, a indevida, porém frequente indagação acerca do passado sexual da vítima (Crenshaw, 1991).

A mulher negra, que, para além da questão de gênero, sofre o impacto do eixo de subordinação racial, vivencia experiências de dominação distintas das mulheres em geral e dos homens negros. Este é o fundamento central da ideia de interseccionalidade, que muito deve à difusão do feminismo negro nos Estados Unidos (Collins, 2015). Autoras como Kimberlé Crenshaw (1991) e Patricia Hill Collins (2016) são expoentes deste conceito que lançou luz à ideia de interação entre dois ou mais vetores de subordinação, considerando que as noções de raça, classe, gênero, sexualidade e outras são fenômenos que se constroem reciprocamente e, assim, criam desigualdades sociais complexas (Collins, 2015).

No que tange à violência sexual, os diferentes marcadores de diferenças podem atuar configurando iniquidades na aplicação da lei ou mesmo na assistência conferida à vítima. Neste sentido, Crenshaw (1991) observou que as mulheres negras, apesar de serem mais vitimadas sexualmente, têm menos chances de dar prosseguimento a uma ação criminal (reportar o caso, levar a julgamento e obter condenação do agressor). Tal fato se dá, em grande medida, pela construção do estereótipo da sexualidade negra. Assim, a mulher negra é categorizada como "mulher má”, aquela que não pode ser estuprada; logo, uma suposta agressão a uma mulher negra é vista como menos crível (porque ela é sexualmente voraz) ou menos importante, já que o trauma seria menor do que o vivido por uma mulher branca, presumivelmente "recatada" (Crenshaw, 1991).

Esta associação da mulher negra à sexualidade agressiva, que se formou no imaginário social desde a escravidão, período em que o acesso ao corpo da escrava negra era também considerado um direito da elite masculina branca, facilita a utilização de estereótipos de gênero e raça como justificativas ou “atenuantes” para ataques sexuais generalizados (Romio, 2013).

Racismo e machismo combinam-se e criam uma vulnerabilidade dupla para a mulher negra. Essa vulnerabilidade dupla deve ser compreendida não em termos meramente aditivos, mas sim nos moldes do mencionado conceito de interseccionalidade: ou seja, racismo e machismo interconectados criam experiências de opressão únicas para as mulheres negras (Crenshaw, 1992) ${ }^{29}$.

29 "Considerando que a discriminação racial é frequentemente marcada pelo gênero, pois as mulheres podem às vezes vivenciar discriminações e outros abusos dos direitos humanos de uma maneira diferente dos homens, o imperativo de incorporação do gênero põe em destaque as formas pelas quais homens e mulheres são diferentemente afetados pela discriminação racial e por outras intolerâncias correlatas. Portanto, a incorporação do 
Há, ressalte-se, uma série de dificuldades para a articulação dessas experiências de opressão. Com efeito, tanto o movimento feminista quanto o movimento antirracismo têm seus focos específicos. Contudo, embora a mulher negra pertença formalmente aos dois grupos, sua condição específica, seus interesses interseccionais, não são abarcados por nenhum dos movimentos (Crenshaw, 1992).

Embora toda mulher compartilhe o interesse em eliminar a dicotomia mulher boa/mulher má, não há dúvidas de que mulheres brancas e negras experimentam o poder opressivo desta classificação de maneiras distintas: a mulher branca é julgada por seu comportamento; a mulher negra, pelo que ela é (Crenshaw, 1991, p. 1280). Cossins (2003, p. 94), a propósito, afirma que o sistema penal acaba criando uma "hierarquia das mulheres", cujo ápice é ocupado pelas mulheres "brancas e bem-comportadas", as quais merecem ampla tutela penal; em segundo escalão estariam as mulheres "brancas e más", ou seja, as que desviam do padrão de feminilidade virtuosa; por fim, no último patamar restariam as mulheres negras, cujas práticas sociais são frequentemente consideradas irrelevantes, já que a promiscuidade e a falta de credibilidade são presumidas.

\section{CONCLUSÃO}

A vitimodogmática é um ramo das ciências penais que trata de como o comportamento da vítima pode ter reflexos na reprovabilidade da conduta do autor. Embora tenha extrema importância, por evitar assimetrias desproporcionais de deveres, seu uso abusivo pode causar desproteção legal.

Essa hipótese pode ser verificada no uso inadequado da vitimodogmática nos delitos de estupro. Com efeito, o passado sexual da vítima, seus hábitos, suas vestimentas e outras

gênero, no contexto da análise do racismo, não apenas traz à tona a discriminação racial contra as mulheres, mas também permite um entendimento mais profundo das formas específicas pelas quais o gênero configura a discriminação também enfrentada pelos homens" (Crenshaw, 2002, p. 173). Cossins, a propósito, lembra que as mulheres de populações minoritárias, quando vitimadas por seus pares (isto é, por homens pertencentes a minorias) ainda têm de enfrentar o dilema: sofrer calada ou buscar proteção jurídica e correr o risco de perpetuar a violência policial constantemente sofrida pelos homens de seu grupo social: "For black and indigenous women, this vulnerability produces for them a unique dilemma: not only must they deal with their own experiences of victimization but they must also deal with the victimization of their own men by a criminal justice system that has historically perpetrated violence and injustice against black and indigenous men” (Cossins, 2003, p. 91). 
características pessoais não podem ser considerados como comportamentos de risco, o que reduziria ou mesmo eliminaria a responsabilidade do agressor. Basta, para a configuração do estupro, a ausência de consentimento para a prática de ato libidinoso. E, ressalte-se, não há que se falar em consentimento presumido e, muito menos, em falha de comunicação. $O$ consentimento deve ser inequívoco.

Portanto, o âmbito de aplicação da vitimodogmática e do princípio da autorresponsabilidade não se estende aos delitos sexuais. Mas a impropriedade dogmática não é a única razão para não se indagar de questões vitimodogmáticas nos estupros. Políticocriminalmente, discussões acerca dos deveres de proteção da vítima de crimes sexuais criam uma significativa lacuna de proteção. Tal lacuna é mais evidente quando as vítimas são mulheres negras. Com efeito, nestes casos, os "comportamentos de risco" são pressupostos, de modo que a vítima não tem nem mesmo a chance de ser julgada por seu real comportamento.

A valoração dos corpos envolvidos, carregados de sentidos culturais, acaba por substituir, em um primeiro momento, a discussão vitimodogmática. Assim, o homem negro é visto como violador em potencial, garantindo maior probabilidade de aceitação da palavra da vítima (desde que seja branca). Por outro lado, quando a vítima é uma mulher negra, sua versão é mais facilmente contestada e seu comportamento (real ou presumido) é levado em consideração para redução ou eliminação da responsabilidade do agressor. Em um segundo momento, entretanto, diante da impossibilidade de a decisão traduzir explicitamente preconceitos de quem julga, a vitimodogmática passa a exercer sua menos nobre função: legitimar e racionalizar desproteções e persecuções legais.

Submetido para avaliação em 28 de Fevereiro de 2018

Aprovado para publicação em 04 de Junho de 2018

\section{BIBLIOGRAFIA}

Amaral, C. d. (2007). Bases Teóricas da Ciência Penal Contemporânea. São Paulo: IBCCRIM.

Bhabha, H. K. (2013). O local da cultura (2 ed.). (M. Ávila, Trad.) Belo Horizonte: Editora UFMG. 
Bijleved, C. (2007). Sex Offenders and Sex Offending. Crime and Justice, 35.

Bittencourt, E. d. (1978). Vitima (2 ed.). São Paulo: Editora Universitária de Direito.

Blasco, B. D. (2009). ¿Hacia el Derecho penal de la postmodernidad? Revista Electrónica de Ciencia Penal y Criminología.

Bottini, P. C. (2007). Crimes de perigo abstrato e princípio da precaução na sociedade de risco. São Paulo: RT.

Buergo, B. M. (2001). El derecho penal en la sociedad del riesgo. Madrid: Civitas.

Bung, J. (2016). Fünf Grundprobleme des heutigen Strafrecht. Zeitschrift für Internationale Strafrechtdogmatik, 6.

Carvalho, A., \& Júnior, J. R. (2017). Limites da vitimodogmática: o âmbito de aplicação do princípio da autorresponsabilidade. In: E. S.-D. (org.), O lugar da vítima nas ciências criminais. São Paulo: LiberArs.

Cerqueira, D., \& Coelho, D. d. (2014). Estupro no Brasil: uma radiografia segundo os dados da Saúde. Instituto de Pesquisa Econômica Aplicada (IPEA), Brasília.

Coetzee, J. M. (2016). Desonra (4 ed.). (J. R. Siqueira, Trad.) São Paulo: Companhia das Letras.

Collins, P. H. (2015). Intersectionality's definitional dilemmas. Annual Review of Sociology, 1-20.

Collins, P. H., \& Bilge, S. (2016). Intersectionality. Cambridge: Polity Press.

Comack, E., \& Peter, T. (2005). How the Criminal Justice System Responds to Sexual Assault Survivors: The Slippage between "Responsibilization" and "Blaming the Victim". Canadian Journal of Women and the Law, 17.

Cossins, A. (2003). Saints, Sluts and Sexual Assault: Rethinking the Relationship between Sex, Race and Gender. Social \& Legal Studies, 12.

Crenshaw, K. (1991). Mapping the Margins: Intersectionality, Identity Politics, and Violence Against Women of Color. Stanford Law Review, 43.

. (1992). Race, Gender, and Sexual Harassment. Southern California Law Review, 65.

. (2002). Documento para o encontro de especialistas em aspectos da discriminação racial relativos ao gênero. Estudos Feministas, 10.

Darley, J. M. (2009). Morality in the Law: the psychological foundations of citizens' desires to punish transgressions. Annual Review of Law and Social Science, 5.

Devlin, P. (2010). La imposición de la moral. (M. Á. al., Trad.) Madrid: Dykinson. 
Dias, J. d. (1999). Fundamento, sentido e finalidades da pena criminal. In: J. d. Dias, Questões fundamentais do direito penal revisitadas. São Paulo: Revista dos Tribunais.

Estrich, S. (1987). Real Rape. Massachusetts: Harvard University Press.

Frommel, M. (1987). Wie kann die Staatsgewalt die Frauen vor sexueller Gewalt schützen? Zeitschrift für Rechtspolitik, 7.

Hart, H. L. (1987). Direito, liberdade, moralidade. (G. P. Santos, Trad.) Porto Alegre: SAFE.

Hassemer, W. (1999). Persona, mundo y responsabilidad. Bases para una teoría de la imputación en Derecho Penal. (F. M. Pita, Trad.) Valencia: Tirant lo Blanch.

Hidalgo, P. H. (2015). Análisis de la violencia de pareja bidereccional desde un punto de vista victimodogmático. Revista Electrónica de Ciencia Penal y Criminología, 17.

Hungria, N. (1981). Comentários ao Código Penal (5 ed., Vol. 8). Rio de Janeiro: Forense.

Husak, D. (2008). Overcriminalization. The limits of the criminal law. New York: Oxford University Press.

Kalunta-Crumpton, A. (2010). History: Race relations and justice. In: A. Kalunta-Crumpton, Race, Crime and Criminal Justice: International perspectives. Londres: Palgrave Macmillan.

Kindhäuser, U. (2008). Teoría de las normas y sistemática del delito. Lima: ARA Editores.

Machado, A. A. (2013). Curso de Processo Penal (5 ed.). São Paulo: Atlas.

Meléndez-Cardona, D. (2014). Análisis sobre la conducta criminal de violadores seriales en casos ocurridos en Bogotá, D. C. (2008-2012). Criminalidad, 56(1).

Menachem, A. (1967). Victim Precipitated Forcible Rape. The Journal of Criminal Law, Criminology and Police Science, 58.

Moreno, M. H. (2011). Apropiación indebida. Defraudación de fluido eléctrico. In: M. P. (dir)., Lecciones de derecho penal. Parte especial. Adaptadas a la ley orgánica 5/2010 de reforma del código penal (Vol. Tomo II). Madrid: Editorial Tecnos.

Oliveira, A. S. (1999). A vítima e o direito penal: uma abordagem do movimento vitimológico e de seu impacto no direito penal. São Paulo: Revista dos Tribunais.

Ordeig, E. C. (2005). Imputación objetiva y conducta de la víctima. Anuario de Derecho Penal y Ciencias Penales, LVIII.

Pastana, D. R. (2003). Cultura do medo: reflexões sobre violência criminal, controle social e cidadania no Brasil. São Paulo: IBCCRIM.

Pateman, C. (1993). O contrato sexual. (M. Avancini, Trad.) São Paulo: Paz e Terra. 
Patton, T. O., \& Snyder-Yuly, J. (2007). Any Four Black Men Will Do: Rape, Race, and the Ultimate Scapegoat. Journal of Black Studies, 37.

Pawlik, M. (2010). ¿Engaño por medio del aprovechamiento de defectos de organización ajenos? Acerca de la distribución de riesgos conforme al \$263 STGB en casos de errónea acreditación en cuenta y constelaciones emparentadas. In: M. Pawlik, La libertad institucionalizada: estudios de filosofía jurídica y derecho penal. Madrid: Marcial Pons.

Perin, A. (2016). La contribución de la víctima y la imputación objetiva del resultado en la teoría del delito imprudente. Un estudio comparado en materia de prevención de riesgos laborales. Revista Electrónica de Ciencia Penal y Criminología, 18.

Randall, M. (2010). Sexual Assault Law, Credibility, and "Ideal Victims": Consent, Resistance, and Victim Blaming. Canadian Journal of Women and the Law, 22.

Ripollés, J. L. (2008). La política legislativa penal iberoamericana a principios del siglo XXI. In: J. L. Ripollés, \& O. G. (coord.), La política legislativa penal iberoamericana en el cambio de siglo. Buenos Aires: Editorial B de F.

Rodríguez, C. I. (2010). La incidencia del comportamiento de la víctima en la responsabilidad penal del autor (hacia una teoría unívoca). Revista Derecho Penal y Criminología, XXXI(90).

Romio, J. A. (2013). A vitimização de mulheres por agressão física, segundo raça/cor no Brasil. In: M. M. (org.), Dossiê mulheres negras: retrato das condiçôes de vida das mulheres negras no Brasil. Brasília: Ipea.

Ross, J. (2010). Blaming the victim: "Consent" within the fourth amendment and rape law. Harvard Journal on Racial \& Ethnic Justice, 26.

Sánchez, J. M. (2001). La expansión del derecho penal: aspectos de la política criminal en las sociedades postindustriales (2 ed.). Madrid: Civitas.

Sánchez, J.-M. S. (2001). La consideración del comportamiento de la víctima en la teoría jurídica del delito. Observaciones doctrinales y jurisprudenciales sobre la "victimo-dogmática". Revista Brasileira de Ciências Criminais, 9.

Schneider, H. J. (1994). Temas principales y deficiencias en el actual pensamiento victimologico. Derecho Penal y Criminología, 16.

Silveira, R. d. (2008). Crimes sexuais: bases críticas para a reforma do direito penal sexual. São Paulo: Quartier Latin.

South, S., \& Felson, R. B. (1990). The Racial Patterning of Rape. Social Forces, 69.

Souza, J. G. (1998). Vitimologia e violência nos crimes sexuais: uma abordagem interdisciplinar. Porto Alegre: SAFE.

Torres, M. E. (2010). Algunas consideraciones victimodogmáticas en los delitos sexuales. Ars boni et aequi, 6(2). 
Wittg, P. (2007). Teoría del bien jurídico, harm principle y delimitación de ámbitos de responsabilidad. In: R. Hefendehl (Ed.), La teoría del bien jurídico. ¿Fundamento de legitimación del Derecho penal o juego de abalorios dogmático? Madrid: Marcial Pons.

Wriggins, J. (1983). Rape, Racism, and the Law. Harvard Women's Law Journal, 6.

Young, V. D. (1980). Women, Race, and Crime. Criminology. 18(1) 